\title{
ADHESION AND BONDING BETWEEN STEEL PIPE AND CEMENT/SPACER/MUD SYSTEM
}

\author{
ZHIDONG ZHANG*, GEORGE W. SCHERER $\uparrow$ AND ROBERT K. PRUD'HOMME $\uparrow \dagger$ \\ "CEE, Princeton University \\ Princeton, NJ USA \\ E-mail: zhidongz@princeton.edu \\ ${ }^{\dagger}$ CEE, Princeton University \\ Princeton, NJ USA \\ E-mail: scherer@princeton.edu \\ ${ }^{\dagger \dagger} \mathrm{CBE}$, Princeton University \\ Princeton, NJ USA \\ E-mail: prudhomm@princeton.edu
}

Key words: Adhesion, Interfacial fracture toughness, Oil-well cementing, Non-Aqueous drilling fluids, Spacer

\begin{abstract}
The principle function of oil-well cementing is to bond and support the casing, and to provide downhole zonal isolation. However, the residual non-aqueous drilling fluids (oil-based mud) on the surface of steel pipe can weaken the bond to the hardened cement. The most practical way to analyze the bonding between cement slurry and steel pipe is to directly measure adhesion between these two materials. In the present study, the cement cylinder and the steel coin are separately fixed in two sides of a Brazilian disk, and then the force is applied along the diameter of the disk, at an angle to the interface between the cement and steel. The preliminary results from Brazilian disk tests show that shear bond strength is quite different for the two commercial spacers. Another important factor is the surface condition. Polished, sandblasted and rusted coins are used to examine the effect of surface conditions. Better adhesion is obtained on rusted steel surfaces.
\end{abstract}

\section{INTRODUCTION}

In oilfield cementing, cement is used to seal the annulus between the steel pipe and the geological formation to stabilize the pipe and to prevent migration of fluids between hydrocarbon reservoirs and aquifers (i.e., to provide zonal isolation). During the course of drilling operations, non-aqueous drilling fluids, normally oil-based muds (OBM), are often used to improve drilling efficiency. The OBM can alter the surface condition of steel pipes from water-wet to oil-wet by adding a thin layer of mud on the surface.
Unfortunately, drilling fluids and cements are not naturally compatible with one another, so the residual drilling fluids on the surface of steel pipe can weaken the bond to the hardened cement [1]. Failure to provide efficient bonding can cause such problems as high annular pressure at the surface, blowouts, poor zonal isolation, loss of gas to non-productive zones, low producing rates, etc. All of these are costly to repair. To improve mud removal effectiveness, a series of aqueous cement "spacers" have been used to displace the drill fluids from the oil wellbore before pumping 
the cement slurry. Spacers may contain viscosifiers, weighting material, surfactants, solvents, mutual solvents, etc. The components can all simultaneously influence the performance and the ultimate success of spacers [2]. To investigate the efficiency of drilling fluid removal by spacers, we can measure the amount of residual mud on the surface of the casing [3]. Since the ultimate purpose of cementing is to provide a good bond, the goal is to directly measure the adhesion and bond strength between the hardened cement and steel.

In concrete technologies, pull-out tests are commonly used to study bond strength between rebar and concrete [4]. However, circular steel coins were used in the previous studies [3] due to the ease of measuring the surface condition, and the coin is not a good geometry for a pull-out test. Thus, in this paper, we adapt a modified Brazilian disk as sample holder which can secure both cement cylinders and steel coins [5]. Another reason for choosing the Brazilian disk is that the ultimate goal of this study is to quantify the interfacial fracture toughness properties between cement and steel. Because of time limitation, the paper only presents the shear bond strength results. When compressing the disk at an angle to the interface between the cement and steel, the assembly is apt to break down along the interface. There are lots of studies which have shown that surface condition influences the wettability of a surface [6-8]. Presumably, the bond strength is also affected by surface condition. This will be discussed in the present paper.

\section{EXPERIMENTS}

\subsection{Materials}

The drilling fluid used was a synthetic oilbased system (BAKER HUGHES, Rheo-logic) having density of $1,105 \mathrm{~kg} / \mathrm{m}^{3}$. Cement slurries were prepared and preconditioned according to the API Specification 10 [9] using distilled water and a Class $\mathrm{H}$ oil-well cement. The compositions of cement slurries are shown in Table 1. Solid additives were blended with the cement powder. Liquid additives were added to the water prior to mixing with cement.

Table 1: Compositions of cement slurry (Unit: $\mathrm{kg} / \mathrm{m}^{3}$ )

\begin{tabular}{lll}
\hline Compositions & Weight & Note \\
\hline Cement & 1403 & Class H \\
\hline Water & 522 & Deionized water \\
\hline Antifoam & 2.5 & Liquid additive \\
\hline Dispersant & 4.3 & Liquid additive \\
\hline Fluid loss & 11.7 & Liquid additive \\
\hline Retarder & 5.7 & Liquid additive \\
\hline $\begin{array}{l}\text { Potassium } \\
\text { chloride }\end{array}$ & 15.7 & Solid additive \\
\hline
\end{tabular}

To evaluate the performance of spacers, two types of spacers, microparticle and microemulsion, are compared in this study (see Tables 2 and 3). The density of each spacer is $1,740 \mathrm{~kg} / \mathrm{m}^{3}$, which is higher than OBM, but lower than cement slurry. This ensures that spacer can be easily pumped into the wellbore and can push OBM out. The microparticle spacer is a kind of displacement fluid using barite as the main component. Barite has specific gravity of 4.5 , so it is used as a weighting agent in the spacer. The particle size of the ground barite is in the micron range, so it does not damage the bearings of the drill bit. Moreover, barite is chemically inert under downhole conditions. Water in this spacer causes it to be incompatible with OBM. Hence, the surfactant with hydrophobic and hydrophilic moieties is needed to facilitate the phase inversion of OBM. The displacement of OBM is mainly achieved by the solubilization process [10].

Table 2: Design of microparticle spacer (Unit: $\mathrm{kg} / \mathrm{m}^{3}$ )

\begin{tabular}{lll}
\hline Materials & Weight & Note \\
\hline Barite & 142 & Solid \\
\hline Microparticle & 17 & Solid \\
\hline Water & 117 & Deionized water \\
\hline
\end{tabular}

In recent years, because of the concerns about health, safety, and the environment, the use of solvent/surfactant-based spacers has been limited, as the industry moves to greener technologies. Using microemulsion technology in downhole operations has gained popularity $[11,12]$. Microemulsion formulations can 
create an ultra-low interfacial tension between the oil and water phases so that the spacer exhibits equal affinity for the oil and water phases. Therefore, OBM displacement by microemulsion spacer is based on the microemulsification mechanism. Previous studies have shown that, compared to microparticle spacer, microemulsion spacer can improve mud removal [3].

Table 3: Design of microemulsion spacer (Unit: $\mathrm{kg} / \mathrm{m}^{3}$ )

\begin{tabular}{lll}
\hline Materials & Weight & Note \\
\hline Microemulsion & 268 & Liquid \\
\hline Surfactant & 8 & Liquid \\
\hline
\end{tabular}

\subsection{Surface roughness measurements}

In the field, most pipelines are made of carbon steel. Once corrosive water wets the pipe wall (primarily during storage in the field), corrosion can occur. Thus, in this study, the effect of surface corrosion on wettability was investigated. The initially clean coins were corroded by exposure to the corrosive solution which is a mixture of acid, hydrogen peroxide and salt (see Appendix). The original coins came with finish marks so the surface is anisotropic. This can cause mud to distribute non-uniformly on the surface, which we need to avoid. Coins were polished before any tests. To create different surface conditions, some originally clean coins were sandblasted, which is a typical treatment in the field. Overall, three types of surface conditions were compared in this study: polished, sandblasted and rusted.

The surface roughness of coins was measured by a profilometer (Olympus LEXT OLS4100 laser scanning digital microscope) to assess the effect of surface condition. The resolution is $0.624 \mu \mathrm{m}$, and an area of $624 \times 624 \mu \mathrm{m}^{2}$ was measured in one location. A total of 9 locations were chosen for each coin. The 3D images of the clean, sandblasted and rusted surfaces are shown in Figure 1. The surface contour of the rusted coin is rougher than that of the polished and sandblasted surfaces. Our studies have shown that a marginally thicker oil film after exposure to the spacer fluids is associated with local roughness on the surface.

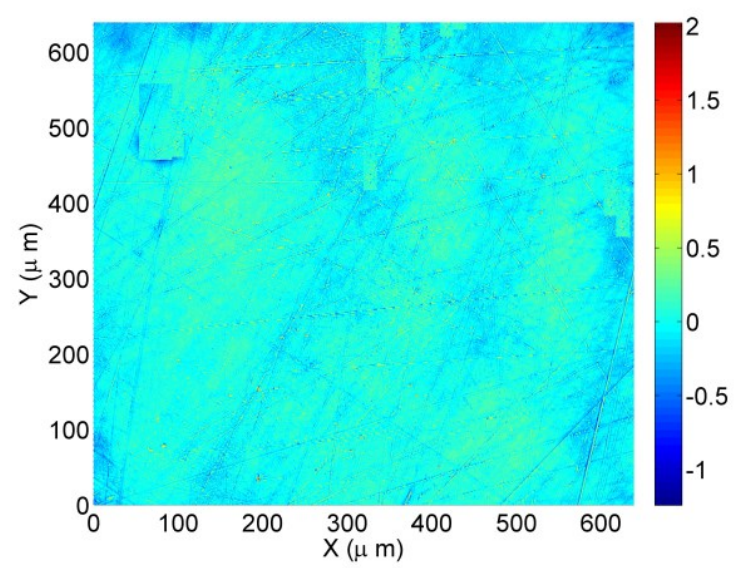

(a) Polished coin

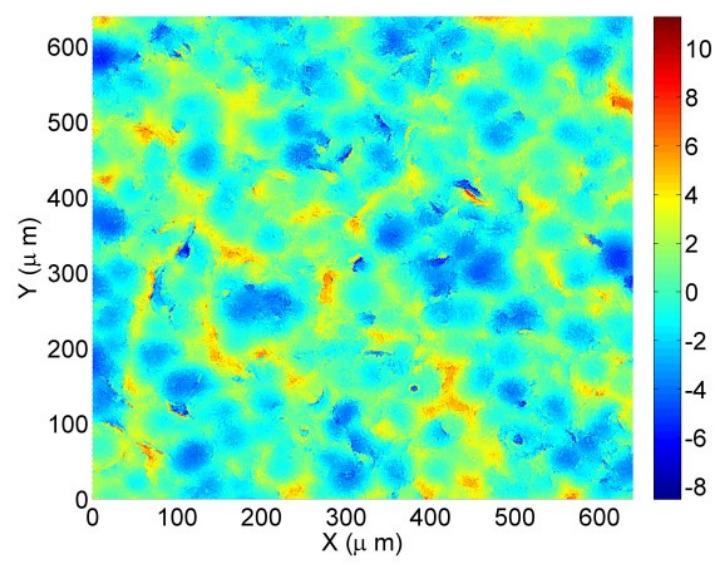

(b) Sandblasted coin

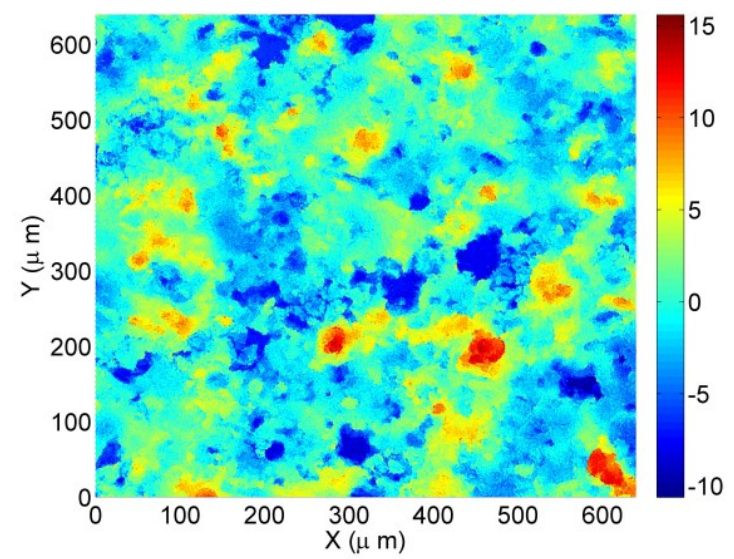

(c) Rusted coin

Figure 1: Images measured by laser microscope for different pretreated coins.

Surface roughness can be parameterized in a number of ways. A summary of these parameters as stated by the ISO 25178 is presented in Table 4. The most widely used roughness parameter is $S_{a}$, which is the arithmetic mean height of the surface. $S_{z}$ gives 
the peak to peak value and $S_{q}$ is the root mean square height. The ratio between the interfacial and projected area $S_{d r}$ gives the additional surface area contributed by the texture. This parameter can be used to calculate the roughness ratio $r$ according to following relation [6].

$$
\mathrm{r}=1+\frac{S_{d r}}{100}
$$

Table 4: Roughness parameters

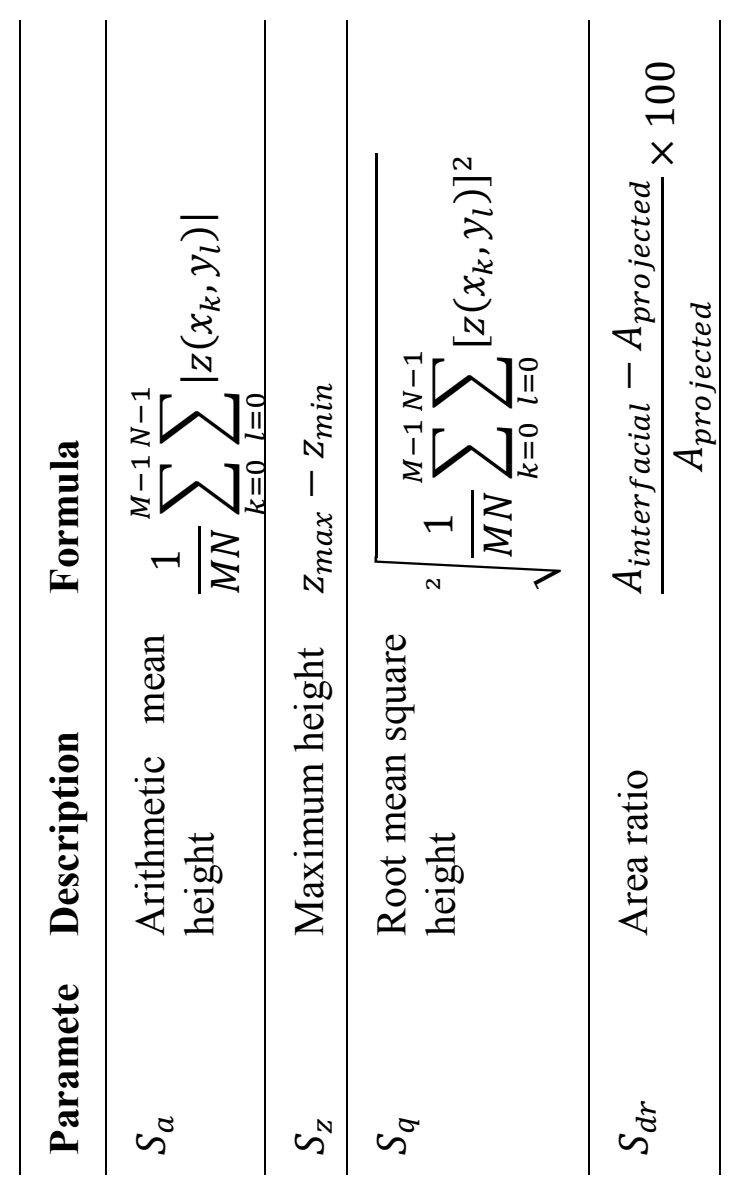

\subsection{Specimen preparation}

Specimen preparation for the shear bond strength test is similar to our previous studies [13] which tried to measure the residual OBM thickness on the surface of steel pipes (see Figure 2). The procedure attempts to simulate the shear rates used in the oilfield cementing operation. The $10-\mathrm{min}$ contact time is generally used in the field.

Prior to the test, coins were washed by detergent to remove any trace of organics. Isopropanol was then used to further clean the coin. The plastic tube was greased to reduce the bonding between cement and the inner wall of the tube. This can minimize the risk that shrinkage of cement during hydration will pull cement away from coins. After two cement flushings, cement was drained and only a layer of cement paste about $1 \mathrm{~cm}$ thick was left in the tube. Above the cement slurry, water was added to keep the material wet, which can reduce the chemical shrinkage and drying shrinkage effect.

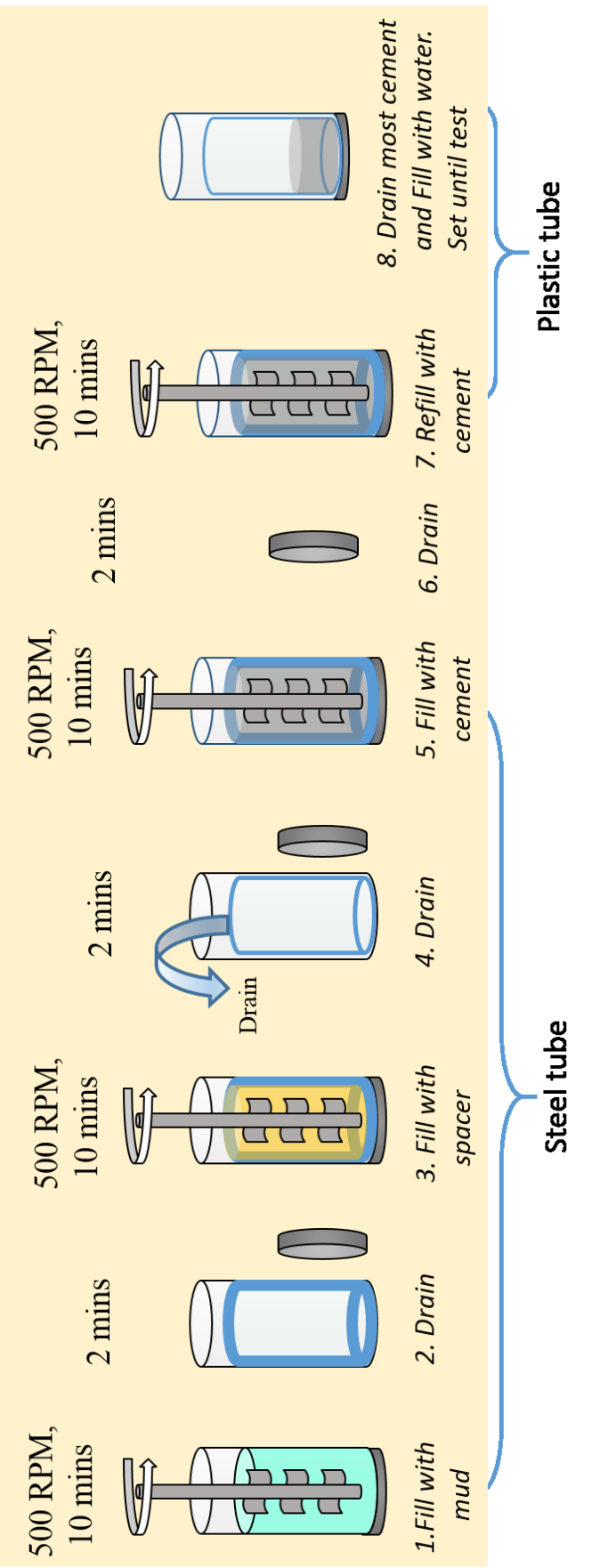

Figure 2: Experiment procedure for preparing specimen. 


\subsection{Shear bond strength test}

After a two-day aging period, the specimen is ready for the shear bond strength test. A sample holder was built to secure the specimen (see Figure 3). In principle, the load angle (angle between the interface and the loading direction) can be adjusted from $0^{\circ}$ to $25^{\circ}$, which corresponds to pure mode I and pure mode II crack opening [5]. In the present paper, we only show results from load angle $\theta$ $=22^{\circ}$, which includes both mode I and II.

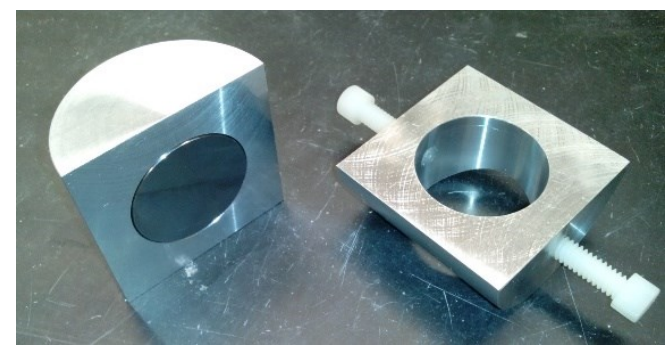

(a)

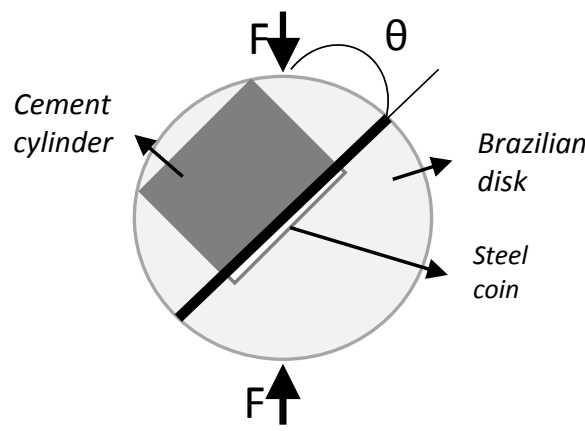

(b) Schematic drawing of shear bond strength test

Figure 3: Sample holder and experiment setup.

\section{RESULTS AND DISCUSSION}

\subsection{Surface roughness}

Figure 1 clearly shows that the three surface treatments created different surface morphologies. No obvious valleys and peaks can be seen for the polished surface. If one only looks at the colorbars, which represent roughness parameter $S_{z}$, there is no significant difference between sandblasted and rusted coins. However, the shapes of valleys and peaks for these two conditions are very different. Spherical abrasive particles created circular patterns on the sandblasted surface, and these circles are very similar. Rust growth depends on the local morphology and chemistry, so we see various sizes and depths of valleys and peaks in Figure 1c.

These observations are quantified in Figure 5 , in which the three points on each curve represent the three surface conditions (from left to right): polished, sandblasted and rusted. Big differences can be seen in $S_{a}$ and $S_{q}$ for the three surface conditions, while for sandblasted and rusted surfaces $S_{Z}$ and $\mathrm{r}$ do not show significant difference. $S_{Z}$ measures the difference between the highest and lowest points in the measured area. This means that $S_{z}$ does not represent the average condition and has a large randomness depending on the location measured.

Roughness parameter $r$ strongly depends on the resolution of the measurement. Finer structure and higher interfacial area can be captured if high resolution is used. Unfortunately, the resolution $0.625 \mu \mathrm{m}$ does not seem able to distinguish the sandblasted and rusted coins.

\subsection{Shear bond strength}

When compressing the assembly, the applied force is resolved into two directions, shear and compression. Shear force tends to break the assembly, while compressive force pushes the materials into contact and resists shear. The shear bond strength is formulated as

$$
\sigma_{s}=\frac{F_{\max } \cos \theta}{\pi r^{2}}
$$

When the load angle $\theta=22^{\circ}$, about $93 \%$ of load force is applied in the shear direction. A typical sample fracture curve is displayed in Figure 4.

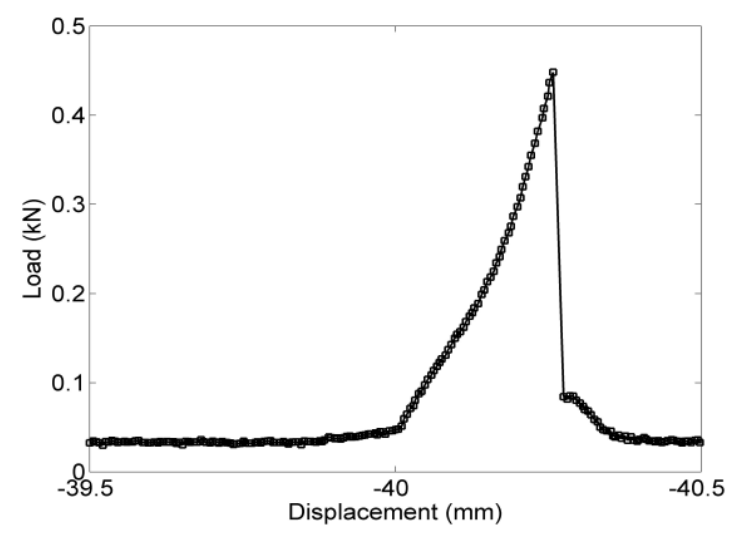

Figure 4: Typical load-deflection curve. 

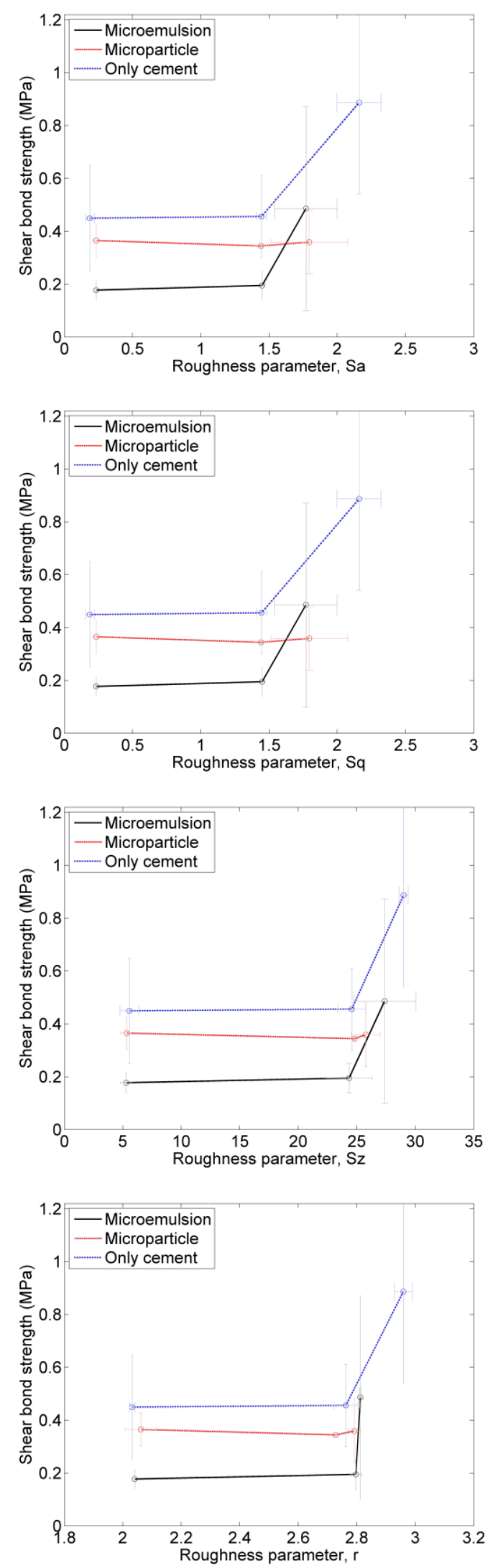

Figure 5: Shear bond strength vs. surface roughness parameters for cases of coins flushed by microparticle spacer, microemulsion spacer and only by cement. Error bars represent the standard deviation.
Calculated shear bond strength versus surface roughness parameters $\left(S_{a}, S_{a}, S_{a}\right.$ and $r)$ are shown in Figure 5. The main observations are:

a) If the cement is allowed to set directly on the coin (without drilling fluids and spacer flushings) it always provides better bonding. This confirms that the $\mathrm{OBM} /$ spacers retained on the steel surface reduce the bond strength.

b) For polished and sandblasted surfaces, microparticle spacer provides higher shear bond strength than microemulsion spacer. The main reason is that after spacer flushing there is more microemulsion spacer left on the surface than residual microparticle spacer (see Figure 6, where residual spacer is showed in white or yellow). The contamination by microemulsion spacer can retard the initial setting of cement slurry and reduce the density and strength of the mixture [14].
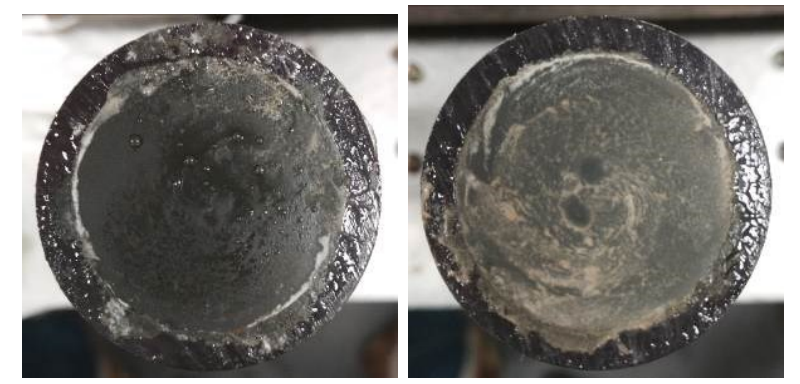

Figure 6: Interfaces of cement cylinders after test (Left: microparticle; Right: microemulsion).

c) One unexpected result is that sandblasted coins provide bond strength similar to polished coins, whether using microparticle spacer, microemulsion spacer or only cement.

d) Rusted coins always provide higher shear bond strength than polished and sandblasted coins. This may be due to differences in the chemical properties of rust and steel, as it has been found that rust can improve the wettability of steel [8], or might simply indicate better mechanical interlocking between cement and the rough surface of the rust. However, the high variability of the results indicates that more 
tests need to be done to explain the behavior of rusted coins.

\section{CONCLUSION}

In this study, a new method to carry out shear bond strength testing between circular steel coins and cement cylinders has been developed. By using this method, the effectiveness of two commercial spacers, microemulsion and microparticle, are compared. For polished and sandblasted coins, microparticle spacer performs better than microemulsion spacer, which is due to more microemulsion spacer left on the coin surface. Among the three surface treatments, rusted coins always show the highest bond strength. This is encouraging, because steel pipes are more or less corroded in the field.

\section{FUTURE WORK}

Tests will be performed at different loading angles and different curing durations. The geometry of specimens used in this study differs from the traditional Brazilian disk, which must have a notch (artificial crack) between the two pieces. Analytical equations are not available to calculate the fracture toughness, because different materials are joined at the interface. One main goal is to use finite element analysis to evaluate the critical stress intensity factors, $K_{I C}$ and $K_{I I C}$.

\section{ACKNOWLEDGMENTS}

Funding for this project is provided by RPSEA through the "Ultra-Deepwater and Unconventional Natural Gas and Other Petroleum Resources" program authorized by the U.S. Energy Policy Act of 2005. The authors would like to thank CSI Technologies, especially Larry Waters and Paul Sonnier, for their support. Special thanks to Professor Soboyejo for his advice on the shear bond test.

\section{Appendix: Preparation of rusted coins}

The procedure used to prepare rusted coins is:

1) Clean the coin with detergent and ethanol, and let it dry.
2) Submerge the coin into vinegar for $1 \mathrm{~min}$ and then let it dry for 5 mins. Repeat 5 times.

3) Prepare the solution by mixing vinegar $(60 \mathrm{ml})$, hydrogen peroxide $(60 \mathrm{ml})$ and salt $(8 \mathrm{~g})$.

4) Submerge the coin into the solution for 1 min and then let it fully dry. Repeat several times until the surface is totally and uniformly covered by rusts.

5) Store the coin in the dry environment for one day.

After the above procedure, the coin should be ready for test.

\section{REFERENCES}

[1] Guillot, D., Hendriks, H., Callet, F., and Vidick, B. 1990. "Mud removal" Well cementing. Ed. Nelson, E.B. Schlumberger Educational Services, pp. 5-01-5-24.

[2] Christian, C.D., Ellis, D.R., Brege, J.J., Quintero, L. and Clark, D.E., 2009, April. The development of an effective waterwetting cement spacer for the displacement of non-aqueous fluids (NAF). In $A A D E$ Technical Conference and Exhibition (pp. 1-5).

[3] Zhang, Z., Scherer G.W., and Prud'Homme R.K., 2016. Effect of surface roughness on the thickness of residual oilbased mud on the steel casing. In draft.

[4] Castel, A. and Foster, S.J., 2015. Bond strength between blended slag and Class $\mathrm{F}$ fly ash geopolymer concrete with steel reinforcement. Cement and Concrete Research, 72, pp.48-53.

[5] Wang, J. S., and Suo, Z. 1990. Experimental determination of interfacial toughness curves using Brazil-NutSandwiches. Acta Materialia. Vol. 38, No. 7, pp. 1279-1290.

[6] Good, R.J., Chaudhury, G.M., and Yeung, C., 1998, December. A new approach for determining roughness by means of contact angles on solids. In First International Congress on Adhesion Science and Technology---invited Papers: Festschrift in Honor of Dr. K1 Mittal on the 
Occasion of His 50th Birthday (p. 181). Vsp.

[7] Nakae, H., Inui, R., Hirata, Y. and Saito, H., 1998. Effects of surface roughness on wettability. Acta Materialia, 46(7), pp.2313-2318.

[8] Lu, W. and Chung, D.D.L., 1998. Effect of rust on the wettability of steel by water. Cement and Concrete Research, 28(4), pp.477-480.

[9] American Petroleum Institute, 1990.

Specification for Materials and Testing for Well Cements, API Spec. 10, 5th edn., American Petroleum Institute, Dallas, TX, USA.

[10]Quintero, L., Christian, C., Halliday, W., White, C. and Dean, D., 2008, April. New Spacer Technology for Cleaning and Water Wetting of Casing and Riser. AADE-08-DF-HO-01, 2008 AADE Fluids Conference and Exhibition, Houston, Texas.

[11]Quintero, L. and Pietrangeli, G.A., 2013, April. Enhanced Oil Solubilization Using Microemulsions With Linkers. In SPE International Symposium on Oilfield Chemistry. Society of Petroleum Engineers.

[12]Quintero, L., Passanha, W.D., Aubry, E. and Poitrenaud, H., 2015, October. Advanced Microemulsion Cleaner Fluid Applications in Deepwater Wells. In OTC Brasil. Offshore Technology Conference.

[13]Choi, M., Scherer, G.W., and Prud'homme, R.K., 2016. Novel methodology to evaluate displacement efficiency of drilling mud using fluorescence in primary cementing. In draft.

[14]Zhang, Z., Scherer G.W., and Prud'Homme R.K., 2016. Properties of cement slurries contaminated by spacers in oil-field cementing. In draft. 